\title{
PENERAPAN TEKNOLOGI AUGMENTED REALITY SEBAGAI SARANA EDUKASI PERKENALAN ALAT MUSIK DENGAN METODE SINGLE MARKER
}

\author{
Tri Mulyadi' ${ }^{1}$, Muhammad Rizal $\mathbf{H}^{2}$, Amran Amiruddin ${ }^{3)}$ \\ ${ }^{1,2,3)}$ Teknik Informatika STMIK AKBA Makassar \\ email :trimulyadix@gmail.com ${ }^{1)}$,rizal@akba.ac.id ${ }^{2}$, amranamiruddin@akba.ac.id ${ }^{3)}$
}

\begin{abstract}
Abstraksi
Augmented Reality (AR) merupakan teknologi yang berkembang saat ini dan sangat diminati sehingga menawarkan peluang baru sebagai media edukasi pengenalan alat musi. Penelitian ini bertujuan untuk merancang aplikasi AR sebagai sarana edukasi perkenalan berbagai macam alat musik dengan metode single marker.Metode yang digunakan pada penelitian ini yaitu metode singe marker. Augmeneted reality dirancang untuk pengenalan alat musik tradisional indonesia, dirancang menggunakan unity, database dengan vuforia dan pembuatan objek 3d meniggunakan skhectup kemudian di paketkan dengan unity. Aplikasi augmented reality di implementasikan pada smartphone android dengan cara menginstal file Alat musik.apk yang di build dengan unity. Dari hasil pengujian yang dilakukan menunjukkan bahwa setiap ukuran marker mempengaruhi batas jarak minimum dan maksimum kamera untuk melakukan tracking pemanggilan objek.
\end{abstract}

\section{Kata Kunci :}

Augmented Reality, Marker, Alat Musik

\section{Pendahuluan}

Sejalan dengan perkembangan zaman, munculah teknologi realitas maya atau biasa disebut dengan virtual reality $(V R)$. Realitas maya yaitu teknologi yang membuat pengguna dapat berinteraksi dengan suatu lingkungan yang disimulasikan oleh komputer (computer-simulated environment), suatu lingkungan sebenarnya ditiru atau terdapat suatu lingkungan baru yang hanya terdapat dalam komputer. Dalam virtual reality, informasi mengenai dunia virtual yang ditampilkan ke indra pengguna dapat bersifat visual (paling umum) menggunakan layar atau head mounted display, audio menggunakan headphone, kontroler, dan bahkan sentuhan menggunakan sarung tangan khusus[1].

Namun, pada perkembangannya virtual reality memiliki cabang baru menyaingi Virtual reality itu sendiri. Teknologi tersebut bernama Augmented Reality (sering disingkat menjadi AR), atau diterjemahkan menjadi realitas tertambah. Kelebihan utama dari Augmented reality dibandingkan Virtual reality adalah pengembangannya yang lebih mudah dan murah sehingga tak seperti virtual reality yang sampai saat ini masih digunakan secara terbatas oleh kalangan tertentu. Berdasarakan penelitian Maulina Fitira Nigsih tahun 2015 yang berjudul Pengaruh Media Pembelajaran Berbasis Augmented Reality terhadap Hasil Belajar Siswa diperoleh hasil bahwa terdapat pengaruh yang signifikan dengan penggunaan media pembelajaran berbasis Augmented Reality terhadap hasil belajar siswa. Nilai rata-rata hasil belajar siswa yang menggunakan media pembelajaran berbasis Augmented Reality lebih tinggi dibanding nilai rata-rata hasil belajar siswa tanpa menggunakan media pembelajaran berbasis Augmented Reality. Teknologi ini apabila digunakan sebagai media pembelajaran maka siswa akan diajak untuk berpikir secara nyata, tanpa harus mendatangkan langsung alat-alat praktiknya[2].

Terkait dengan proses pembelajaran yang sering dilakukan pada semua jenjang pendidikan didalamnya pasti tidak lepas dengan metode dan cara mengajar yang digunakan oleh masing-masing sekolah atau guru. Dengan adanya metode atau cara mengajar yang terapkan pada proses pembelajaran tidak lain adalah untuk mencapai tujuan pembelajaran yang sesuai dengan setiap disimplin ilmu. Pencapaian tujuan terebut dalam dilalui dengan mempengaruhi beberapa aspek pendidikan seperti aspek pemahaman. Aspek pemahaman ini juga tidak bisa berdiri sendiri melainkan harus ada dukungan dari aspek lain yaitu motivasi.

Kelebihan lain dari augmented reality yaitu dapat diimplementasikan secara luas dalam berbagai media. Sebagai contoh penggunaan aplikasi dalam sebuah smartphone (contohnya Android dan iPhone), dalam bingkisan sebuah produk, dan untuk media cetak seperti buku, majalah atau koran. Penggunaan media pendidikan secara tepat dan bervariasi dapat mengatasi sikap pasif pada anak didik. Dalam hal ini media pendidikan berguna untuk, Memungkinkan interaksi yang lebih langsung antara anak didik dengan lingkungan dan kenyataan, memungkinkan anak didik belajar sendiri menurut kemampuan dan minatnya, Dari pendapat-pendapat diatas, dapat dilihat fungsi pentingnya sebuah media untuk membantu atau menunjang proses pembelajaran, agar tujuan pembelajaran dapat dicapai secara optimal.

Banyak metode yang terdapat dalam augmented reality seperti multiple marker, tengible marker, paddle marker, markerless, virtual marker, tetapi dalam pembuatan aplikasi ini saya memilih single marker sebagai metode marker dalam pembuatan 
aplikasi, single marker metode dimana satu marker satu objek, saya menggunakan metode single marker agar memudahkan dalam pemakaian aplikasi nantinya.

Banyak penelitian yang sama dengan penelitian ini seperti "Pengenalan Alat Musik Daerah Berbasis Android Dengan Menggunakan Augmented Reality Pada Siswa Kelas 5 Di Sd Negeri Guyung 02 Kabupaten Ngawi", tetapi didalamnya hanya menampilkan objek $3 \mathrm{~d}$ saja, tetapi di penelitian ini saya menambahkan video agar lebih jelas tentang alat musik tersebut[3].

Berdasarkan permasalahan di atas, media pembelajaran yang dapat dikembangkan adalah media pembelajaran dengan menggunakan teknologi Augmented Reality pada platform Android. Pengembangan media pembelajaran dengan menggunakan teknologi Augmented Reality dapat menjadi salah satu solusi tepat untuk menambah keefektifan dalam pembelajaran. Teknologi ini memungkinkan hal-hal abstrak yang tidak tampak, dapat disimulasikan secara 3 dimensi atau 2 dimensi secara real time dan terkesan nyata. Media pembelajaran ini dapat menjadi bahan pengenalan awal bagi siswa. Diharapkan penggunaan teknologi Augmented Reality mampu menarik minat belajar siswa dan pemahaman siswa sehingga nantinya akan meningkatkan prestasi belajar.

\section{Metode Penelitian}

Dalam Penerapan Teknologi Augmented Reality Sebagai Sarana Edukasi Perkenalan Alat Musik dengan Metode Singel Marker dapat disumsikan sebagai berikut, terdapat 5 objek alat musik dalam sebagai sample dalam penelitian ini, di dalam penelitian ini augmented reality sebagai media interaktif dalam mengetahui info tentang alat musik tersebut.

Alat musik dijadikan objek untuk mentracking gambar agar tampil di layar smartphone dalam aplikasi yang dibuat.

\subsection{Analisis Kebutuhan Sistem}

Analisis dilakukan dengan melakukan analisis kebutuhan (Need Assesment). Analisis kebutuhan adalah proses untuk merepresentasikan informasi, fungsi dan tingkah laku yang dapat diterjemahkan ke dalam data, arsitektur, antarmuka dan komponen. Pada tahap ini dilakukan observasi tentang berbagai macam alat musik untuk mendapatkan informasi tentang kebutuhan media pembelajaran. Dalam analisis kebutuhan sistem di bagi menjadi beberapa bagian yaitu, analisis kebutuhan fungsional dan analisis kebutuhan non fungsional:

\section{Kebutuhan Fungsional}

Sistem harus bisa menampilkan informasi yang sesuai dengan keiginan user terkait dengan aplikasi pengenalan alat musik: a. Sistem harus bisa menampilkan inforamsi tentang alat musik.

b. User dapat menggunakan smartphone untuk menjalankan aplikasi augmented reality.

c. User akan lebih mudah mendapatkan informasi dengan menggunakan aplikasi augmented reality

d. Gambar 3D harus bisa tampil di atas marker yang di sediakan agar sesuai keinginan user.

e. Informasi yang di tampilkan harus sesuai dengan referensi.

\section{Kebutuhan Non Fungsional}

Kebutuhan non fungsional berkaitan dengan perangkat yang akan digunakan serta fungsi dan kinerja semua aplikasi, adapun kebutuhan fungsional yaitu sebagai berikut:

a. Oprasional

1) Android dengan versi jellybean.

2) Ram minimal $1 \mathrm{gb}$.

3) Processor minimal 1.2 Ghz.

b. Informasi

Digunakan untuk menginformasikan mengenai alat musik untuk media pembelajaran.

c. Kinerja

1) Gambar 3D yang di tampilkan minimal $75 \%$ menyerupai dari alat musik seutuhnya.

2) Marker yang digunakan harus cepat dikenali oleh Augmented Reality.

\section{Kebutuhan Hardware dan Software}

Dalam proses pembuatan media pembelajaran alat musik ini, hardware yang dibutuhkan adalah hardware dengan spesifikasi minimum untuk menjalankan program aplikasi pengembangan Augmented Reality. Aplikasi utama untuk mengembangkan teknologi Augmented Reality adalah Unity 3D. Berikut ini spesifikasi hardware minimum untuk menjalankan program aplikasi Unity:

Hardware yang di pakai adalah notebook ASUS $X 454 Y$ Series dengan spesifikasi :

1) Processor AMD A8-7410 APU with AMD Radeon R5 Graphics

2) Hardisk $500 \mathrm{gb}$

3) Ram 4096MB

4) VGA AMD Radeon(TM) R5 Graphics Sedangkan software yang digunakan adalah :

1) Windows 10 Pro 64-bit

2) Unity $3 D$

3) Skectup 2018

\section{Hasil dan Pembahasan Tampilan Icon pada Layar Device Smartphone} Icon aplikasi augmented reality pada device smartphone merupakan tools untuk masuk ke dalam apilikasi ARAlatmusik. Icon ARAlatmusik muncul 
setelah menginstal file apk ARAlatmusik pada smartphone, seperti pada gambar 1 .

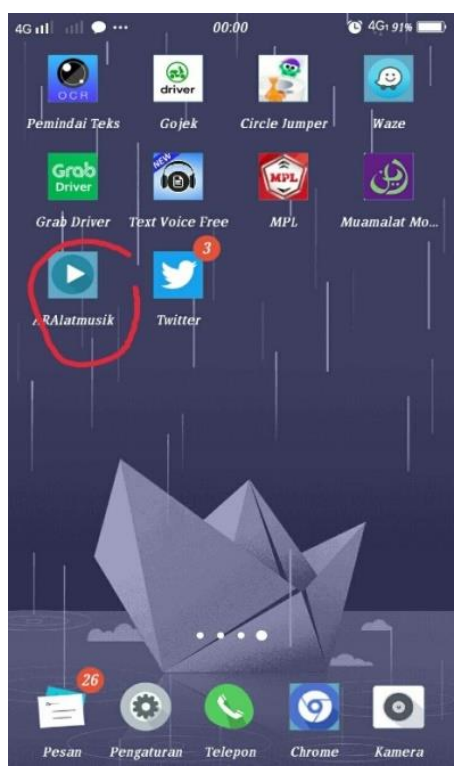

Gambar 1. Tampilan Icon pada layar device smartphone

\section{Main Menu}

Pada perancangan main menu digunakan beberapa fungsi untuk pembuatan tombol yaitu pada main menu terdapat 5 tombol. Dimana setiap tombol memiliki fungsi yang berbeda seperti berikut:

a. Tombol play berfungsi untuk masuk ke menu pilihan alat musik.

b. Tombol info berfungsi untuk masuk ke menu panduan untuk menjalankan aplikasi.

c. Tombol profil berfungsi untuk masuk ke menu profil pembuat aplikasi.

d. Tombol keluar berfungsi untuk keluar dari aplikasi.

Adapun tampilan main mепи seperti terlihat pada gambar 2 .

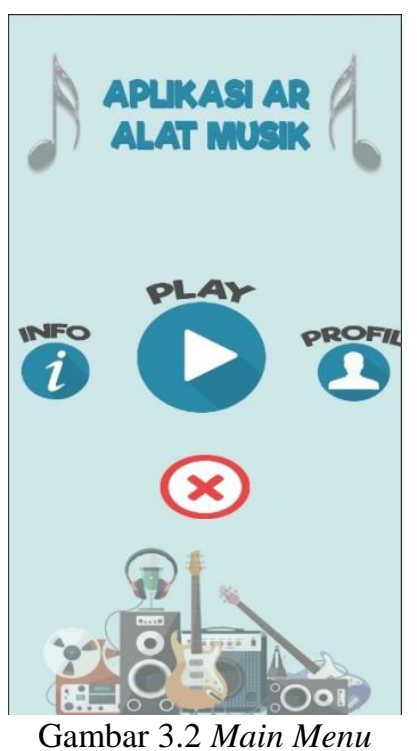

\section{Pengujian Tampilan Objek}

Dalam pengujian ini akan dilakukan dengan melihat objek dari posisi atas dan posisi atas dan posisi layar device saat melintang atau tertidur, pengujian di fokuskan pada usaha verifikasi pada unit terkecil dari desain software,yakni modul pada augmented reality, pengujian unit selalu berorientasi pada pengujian tracking. Pengujian perangkat lunak AR ini akan di uji berdasarkan pada ukuran marker, jarak dan skala posisi objek.

Adapun pengujian yang di lakukan yaitu sebagai berikut

Hasil dari pengujian objek augmented reality pada smartphone vivo v5 menunjukkan bahwa :

a. Pengujia marker gong jawa pada jarak $25 \mathrm{~cm}$ dengan skala $90^{\circ}$ dan $140^{\circ}$ dan objek $3 \mathrm{D}$ terlihat berhasil. pada jarak $35 \mathrm{~cm}$ dengan skala $90^{\circ}$ dan $140^{\circ}$ dan objek 3D terlihat berhasil.

b. Pengujian marker sasando pada jarak $10 \mathrm{~cm}$ dengan skala $90^{\circ}$ dan $140^{\circ}$ dan objek 3D terlihat berhasil. pada jarak $20 \mathrm{~cm}$ dengan skala $90^{\circ}$ dan $140^{\circ}$ dan objek 3D terlihat berhasil.

c. Pengujian marker angklung pada jarak $25 \mathrm{~cm}$ dengan skala $90^{\circ}$ dan $140^{\circ}$ dan objek 3D terlihat berhasil. pada jarak $35 \mathrm{~cm}$ dengan skala $90^{\circ}$ dan $140^{\circ}$ dan objek 3D terlihat berhasil.

d. Pengujian marker saron pada jarak $25 \mathrm{~cm}$ dengan skala $90^{\circ}$ dan $140^{\circ}$ dan objek 3D terlihat berhasil. pada jarak $35 \mathrm{~cm}$ dengan skala $90^{\circ}$ dan $140^{\circ}$ dan objek 3D terlihat berhasil.

e. Pengujian marker kempul pada jarak $25 \mathrm{~cm}$ dengan skala $90^{\circ}$ dan $140^{\circ}$ dan objek 3D terlihat berhasil. pada jarak $35 \mathrm{~cm}$ dengan skala $90^{\circ}$ dan $140^{\circ}$ dan objek 3D terlihat berhasil.

f. Pengujian marker lesung pada jarak $25 \mathrm{~cm}$ dengan skala $90^{\circ}$ dan $140^{\circ}$ dan objek 3D terlihat berhasil. pada jarak $35 \mathrm{~cm}$ dengan skala $90^{\circ}$ dan $140^{\circ}$ dan objek 3D terlihat berhasil. 
g. Pengujian marker dhumbuk pada jarak $25 \mathrm{~cm}$ dengan skala $90^{\circ}$ dan $140^{\circ}$ dan objek 3D terlihat berhasil. pada jarak $35 \mathrm{~cm}$ dengan skala $90^{\circ}$ dan $140^{\circ}$ dan objek 3D terlihat berhasil.

Dari hasil pengujian diatas menunjukkan bahwa setiap ukuran marker mempengaruhi batas jarak minimum dan maksimum kamera untuk melakukan tracking pemanggilan objek.

\section{KESIMPULAN}

Setelah selesainya serangkaian iji coba dan analisa aplikasi augmented reality berbasis mobile smartphone android maka disimpulkan sebagai berikut :

1. Augmeneted reality dirancang untuk pengenalan alat musik tradisional indonesia, dirancang menggunakan unity, database dengan vuforia dan pembuatan objek $3 \mathrm{~d}$ meniggunakan skhectup kemudian di paketkan dengan unity.

2. Aplikasi augmented reality di implementasikan pada smartphone android dengan cara menginstal file Aralatmusik.apk yang di build dengan unity. Dari hasil pengujian yang dilakukan menunjukkan bahwa setiap ukuran marker mempengaruhi batas jarak minimum dan maksimum kamera untuk melakukan tracking pemanggilan objek.

\section{DAFTAR PUSTAKA}

[1] M. Billinghurst, A. Clark, and G. Lee, "A survey of augmented reality," Found. Trends Human-Computer Interact., vol. 8, no. 2-3, pp. 73-272, 2014.

[2] M. F. Ningsih, "Pengaruh Media Pembelajaran Augmented Reality Terhadap Hasil Belajar Siswa Pada Konsep Gelombang,” J. Ilmu Pengetah. Alam, 2015.

[3] A. R. Saputri, P. S. Informatika, F. Komunikasi, D. A. N. Informatika, and U. M. Surakarta, "Pengenalan Alat Musik Daerah Berbasis Android Dengan Menggunakan Augmented Reality Pada Siswa Kelas 5 Di Sd Negeri Guyung 02 Kabupaten Ngawi," 2018. 